\title{
EGFR NM_005228.3:c.2156delG
}

National Cancer Institute

\section{Source}

National Cancer Institute. EGFR NM 005228.3:C.2156de/G. NCI Thesaurus. Code C98533.

A deletion of a guanine at position 2156 from the coding sequence of the EGFR gene. 